\title{
Numerical Response of Migratory Shorebirds to Prey Distribution in a Large Temperate Arid Wetland, China
}

\author{
Yamian Zhang, ${ }^{1}$ Yi Zhu, ${ }^{1}$ Aojie Zuo, ${ }^{1}$ Li Wen, ${ }^{2}$ and Guangchun Lei ${ }^{1}$ \\ ${ }^{1}$ School of Nature Conservation, Beijing Forestry University, Beijing 100083, China \\ ${ }^{2}$ Science Division, Office of Environment and Heritage, Sydney, NSW 2000, Australia \\ Correspondence should be addressed to Guangchun Lei; guangchun8099@gmail.com
}

Received 6 August 2016; Revised 25 October 2016; Accepted 16 November 2016

Academic Editor: Dong Xie

Copyright (c) 2016 Yamian Zhang et al. This is an open access article distributed under the Creative Commons Attribution License, which permits unrestricted use, distribution, and reproduction in any medium, provided the original work is properly cited.

\begin{abstract}
Wuliangsuhai Lake provides important breeding and stopover habitats for shorebirds. The health of this wetland ecosystem is rapidly deteriorating due to eutrophication and water pollution and environmental management is urgently needed. To explore the connections among ecosystem health, prey density, and shorebird populations, we conducted surveys of both the benthic macroinvertebrates and shorebirds in the shorebird habitat of the wetland during the 2011 autumn migration season. The abundance of both shorebirds and benthic macroinvertebrates varied significantly in both space and time. Our data showed a clear association between shorebird populations and the density of benthic macroinvertebrates, which explained $53.63 \%$ of the variation in shorebird abundance. The prey density was strongly affected by environmental factors, including water and sediment quality. Chironomidae were mainly found at sites with higher total phosphorus, but with lower sediment concentrations of $\mathrm{Cu}$. Lymnaeidae were mainly found at sites with a higher $\mathrm{pH}$, lower salinity, and lower concentrations of total phosphorus and $\mathrm{Cu}$. Habitats with very high concentrations of total phosphorus, heavy metals, or salinity were not suitable for benthic macroinvertebrates. Our findings suggest that the reductions of nutrient and heavy metal loadings are crucial in maintaining the ecological function of Wuliangsuhai as a stopover habitat for migratory shorebirds.
\end{abstract}

\section{Introduction}

Shorebirds are known to forage extensively on benthic macroinvertebrates $[1,2]$ and the abundance of benthic macroinvertebrates is likely to be crucial for the short- and long-term survival of shorebirds given their high energy demands during migration and the breeding season [35]. Shorebirds are therefore predicted to show numerical and functional responses to changes in the abundance of their prey $[6,7]$. Migratory shorebirds depend on stopover sites along their migration routes to rest and replenish their energy reserves $[8,9]$. Many factors affect the distribution of their prey species, including water and sediment quality and aquatic plants $[10,11]$, which, in turn, affects the aggregation patterns of foraging shorebirds.

Wuliangsuhai Lake is a key wetland in the vast, arid region of northwest China and provides important breeding and staging habitats for shorebirds in the East Asian-Australasian Flyway [12]. However, as the major area for water storage and the discharge of agricultural drainage in the Yellow River Bend Region [13], the wetland is highly eutrophic [14]. Subsequently, the structure and function of this wetland have gradually changed-for example, the rapid expansion of Phragmites into open water areas has been well documented $[15,16]$. Structural changes in the flora may modify the distribution and abundance of benthic macroinvertebrates [17] and ultimately affect the wetland's function as a feeding ground for shorebirds. However, the relationship between shorebirds and their prey at Wuliangsuhai Lake has not been investigated on any scale and the numerical response of shorebirds to the variation in benthic macroinvertebrates remains unknown.

This study investigated the spatial association of shorebirds and their food resources within Wuliangsuhai Lake. We conducted regular shorebird surveys at three main foraging sites along environmental gradients during the 2011 autumn migration season and sampled the benthic macroinvertebrates and collected data on environmental variables along 


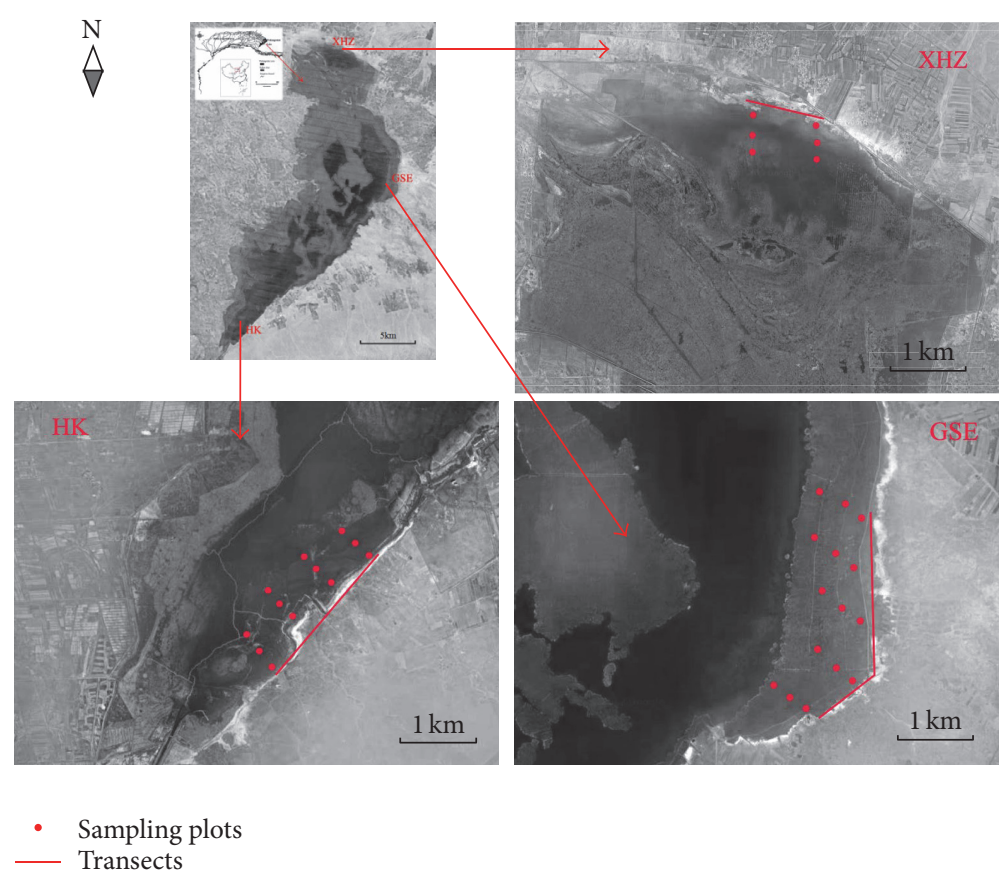

FIGURE 1: Location of Wuliangsuhai Lake and the arrangement of shorebird survey transects (lines) and sampling plots for macroinvertebrates and environmental variables (dots) within the study areas of Gesuer (GSE), Hekou (HK), and Xiaohaizi (XHZ).

the bird survey transects. We aimed to answer two specific questions: (1) what are the important environmental factors for benthic macroinvertebrates and (2) how do shorebirds respond to the changes in their food sources (i.e., the benthic macroinvertebrate density)? This information is crucial in the management of the wetland, particularly as a habitat for migratory waterbirds.

\section{Materials and Methods}

2.1. Study Site. Wuliangsuhai Lake is located in Inner Mongolia, China $\left(40^{\circ} 46^{\prime}-41^{\circ} 05^{\prime} \mathrm{N}, 108^{\circ} 42^{\prime}-108^{\circ} 58^{\prime} \mathrm{E}\right.$ ) (Figure 1), and has an area of $293 \mathrm{~km}^{2}$ and a mean water depth of about $1 \mathrm{~m}$ [17]. The prevailing climate is continental with a low mean annual rainfall $(220 \mathrm{~mm})$, high annual evaporation $(1,502 \mathrm{~mm})$, and a mean annual temperature of $7.0^{\circ} \mathrm{C}$ [18]. The wetland is frozen from November to March and the frostfree period averages 152 days [19]. The main water source is agricultural drainage from the Hetao Irrigation Area. Recent studies have shown that the concentrations of total nitrogen (TN) and total phosphorus (TP) range from 1.44 to 19.31 and 0.024 to $0.057 \mathrm{mg} / \mathrm{L}$, respectively, indicating that the wetland is highly eutrophic $[20,21]$.

About $50.9 \%$ of the wetland surface area is covered by emergent plants and $43.7 \%$ by submerged plants; the remaining $5.4 \%$ consists of sandbars and shoals [22]. The wetland is recognized as one of the most important areas for birds in the vast, arid region of northwest China. A total of 241 bird species has been recorded from 17 orders and 49 families, including black stork (Ciconia nigra), relict gull (Larus relictus), and mute swan (Cygnus olor) [23]. Shorebirds of global conservation importance include far eastern curlew
(Numenius madagascariensis), Asian dowitcher (Limnodromus semipalmatus), black-tailed godwit (Limosa limosa), and Eurasian curlew (Numenius arquata) [12].

2.2. Bird Survey. To investigate the possible associations between shorebirds and benthic macroinvertebrates and to test whether there were variations in the abundance of shorebirds in space and time, data on shorebirds were collected from biweekly surveys during the 2011 autumn migration (late August to early November 2011; eight observation periods) [12]. For the shorebirds, we focused on the families Scolopacidae and Charadriidae because these are the main groups of shorebirds that visit Wuliangsuhai Lake annually $[12,24]$. The surveys were conducted at three main shorebird foraging sites in the wetland: Xiaohaizi (XHZ), Gesuer (GSE), and Hekou (HK) (Figure 1). The sites were chosen to include a range of environmental gradients (e.g., water and sediment quality), although the choice of sites was also influenced by accessibility and safety considerations. XHZ is located in the northernmost part of the wetland, near where drainage water flows into the lake. This area is largely covered by emergent plants, with small patches of shallow water and sandbars. GSE is located on the eastern shore and is mainly covered by emergent and submerged plants; it has the largest proportion of shallow water (depth $<1 \mathrm{~m}$ ) among the three sampling sites. HK is located in the southernmost part of the wetland where the water flows into the Yellow River. It consists of a large area of open water with an area of shallow water near the shore. All three sampling sites provide foraging and resting habitats for shorebirds [12, 22]. A fixed transect with variable lengths was established at each sampling site. Based on the size of the habitat (about $5 \mathrm{~km}^{2}$ at GSE, $4 \mathrm{~km}^{2}$ at $\mathrm{HK}$, and 
$2 \mathrm{~km}^{2}$ at XHZ), the transect length was 4,3 , and $1 \mathrm{~km}$ for GSE, HK, and XHZ, respectively. Each survey was conducted by walking the length of the transect parallel to the lakeshore at a constant speed; the perpendicular searching distance was $0.6 \mathrm{~km}$. Using binoculars $(8 \times 42)$ and telescopes (Swarovski ATS 80 HD $20-60 \times 80)$, we counted and recorded all the shorebirds (in sight or heard). To increase detectability, the surveys were carried out in daytime on clear days and there were at least two fully trained observers for each transect. The variability in observer error was minimized by using the same observers whenever possible throughout the study period. To avoid repeated counting, the three transects were surveyed simultaneously. Visual and/or verbal communication enabled us to avoid duplicate recordings of the same flock of shorebirds by at least two observers. Shorebirds that flew forward were excluded and all the shorebirds present were identified to species level.

2.3. Benthic Macroinvertebrate Survey. Benthic macroinvertebrate samples were collected in the shallow water area of the lake (along the shorebird survey transects) using PVC pipes (7.14 cm diameter) on 17-19 September and 16-17 October 2011. The sampling dates were chosen to reflect the shorebird phenology and represent the "peak" and "postpeak" dates in the autumn migration. As most shorebird species at Wuliangsuhai Lake are unable to forage on prey that is distributed in sediment deeper than $10 \mathrm{~cm}$ [24], only the top sediment layer was collected and analyzed. This depth was sufficient to capture most if not all benthic macroinvertebrates that serve as shorebird prey at Wuliangsuhai Lake. Sediment cores were taken parallel to the transects at regular $100 \mathrm{~m}$ intervals and sampling was repeated every $1 \mathrm{~km}$ (Figure 1). The number of sediment cores collected during each sampling period for the three sampling sites was six, 15, and 12 for XHZ, GSE, and $\mathrm{HK}$, respectively, giving a total of 66 samples. Duplicate samples were collected and the sediment cores were sliced into top $(0-5 \mathrm{~cm})$ and bottom $(5-10 \mathrm{~cm})$ layers, washed, and sorted using a $63 \mu \mathrm{m}$ sieve [25]. The remaining material was preserved in $95 \%$ ethanol and examined microscopically. All individual organisms were counted and because the counts of benthic macroinvertebrate species other than Chironomidae and Lymnaeidae (e.g., the larvae of Tabanidae) were very low, they were grouped together and labeled as "Others" to give three major groups of benthic macroinvertebrate: Chironomidae, Lymnaeidae, and Others. We followed the methods of Epler to identify chironomid larvae [26]. The methods of Merritt et al. [27] and Liu et al. [28] were used to identify other species.

2.4. Substrate Quality and Water Quality. We collected substrate samples at each benthic sampling location using PVC pipes with the same diameter as the macroinvertebrate sampling tubes. The substrate sampling was conducted from 17 to 19 September 2011 and a total of 66 substrate samples were collected, the same number of samples as for the benthic macroinvertebrates. The substrate cores were also divided into top $(0-5 \mathrm{~cm})$ and bottom $(5-10 \mathrm{~cm})$ layers. The samples were analyzed in the laboratory of the Institute of Geographic
Sciences and Natural Resources Research, Chinese Academy of Sciences (Beijing, China) for nitrogen $(\mathrm{N})$, phosphorus $(\mathrm{P})$, organic matter (OM), and heavy metals (As, $\mathrm{Co}, \mathrm{Cu}, \mathrm{Li}, \mathrm{Ni}$, and $\mathrm{Hg}$ ). The $\mathrm{N}$ was determined using an elemental analyzer (Vario MACRO cube, Elementar, Germany). The OM was determined by titration with $\mathrm{K}_{2} \mathrm{Cr}_{2} \mathrm{O}_{7}$. The concentrations of $\mathrm{P}, \mathrm{Co}, \mathrm{Cu}, \mathrm{Li}$, and $\mathrm{Ni}$ were determined by inductively coupled plasma optical emission spectrometry using an Optima 5300 DV spectrometer (Perkin-Elmer, USA) and the concentrations of As and $\mathrm{Hg}$ were determined by inductively coupled plasma mass spectrometry (Elan DRC-e, USA). The substrate was classified into three types based on the particle diameter: sand, sand-mud, and mud.

Water quality measurements were taken at the same time as the benthic macroinvertebrate samples from 17 to 19 September 2011. The in situ water temperature, $\mathrm{pH}$, and dissolved oxygen were measured with a YSI Professional Plus handheld multiple parameter meter (YSI, USA). Chlorophyll a (Chl a) was measured on-site with a Hydrolab MS 5 instrument (HACH, USA). Water samples were collected and preprocessed on site for other parameters, including salinity, TN, and TP. All water samples were processed in the laboratory of Urat Front Banner Environmental Protection Monitoring Station (Inner Mongolia, China) on the sampling day using a TU-1810 UV-VIS spectrophotometer (Persee Incorporated, China).

2.5. Statistical Analyses. We used the nonparametric KruskalWallis test to compare the differences in the abundance of shorebirds, benthic macroinvertebrates, and environmental variables between sampling sites. The Mann-Whitney $U$ test was applied to the benthic macroinvertebrates and quality of substrates collected from different layers to compare the distribution of the variables at different depths.

We applied multiple permutation linear regression to explore the relationship between the abundance of shorebirds and benthic macroinvertebrates. Model selection was based on the resultant $p$ value and the Akaike information criterion [29]. A one-sample Kolmogorov-Smirnov test was used to test the normality of shorebird abundance. The test indicated that the data slightly violated normality $(p=0.087)$. In consideration of the small sample size and possible outliers, we used the permutation test instead of the normal theory test for statistical inference [30].

The distribution variation of benthic macroinvertebrates with environmental gradients was examined using canonical correspondence analysis (CCA) [31] on the $\log (x+1)$ transformed benthic macroinvertebrate density because this allows a quick appraisal of how the community composition varies with environmental gradients. The densities of the three groups of benthic macroinvertebrates at GSE, HK, and XHZ in relation to environmental data were included in the analysis. We pooled the benthic macroinvertebrate density data of the three sediment cores in one sampling transect and used it as the density of the site in the CCA analysis. Thus, we had a total of five sites at GSE, two sites at XHZ, and four sites at HK. Before the CCA, we tested the correlations among these variables using Pearson's correlation coefficient and the strongly correlated variables (i.e., Pearson's $r>0.75$ ) 


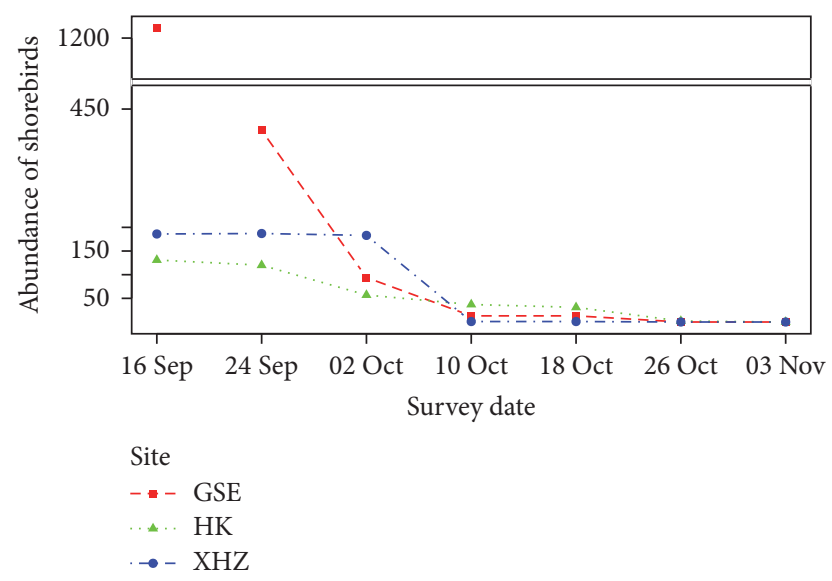

FIGURE 2: Number of shorebirds observed at the three sampling sites of Gesuer (GSE), Hekou (HK), and Xiaohaizi (XHZ) during the autumn migration.

were excluded, including dissolved oxygen, $\mathrm{Chl}$ a, TN, OM, $\mathrm{N}, \mathrm{As}, \mathrm{Co}, \mathrm{Li}, \mathrm{Ni}$, and $\mathrm{Hg}$. A permutation test was used to investigate the correlations between benthic macroinvertebrates and environmental variables. All statistical analyses were performed in R3.2.2 [32].

\section{Results}

3.1. Spatial and Temporal Distribution of Shorebirds. A total of 27 shorebird species with over 3,300 individuals were recorded in the 2011 autumn migration season at Wuliangsuhai Lake. The three most abundant species, blacktailed godwit, spotted redshank (Tringa erythropus), and Pacific golden plover (Pluvialis fulva) comprised $83 \%$ of the shorebird population; Northern lapwing (Vanellus vanellus), Kentish plover (Charadrius alexandrinus), and black-winged stilt (Himantopus himantopus) made up another 13\% of the shorebirds. The total number of shorebirds decreased sharply after September and then decreased gradually until the end of migration season on 6 November 2011 (Figure 2).

The number of shorebirds at the three sampling sites was significantly different (Kruskal-Wallis test, $p=0.030$ ). At the early stage of the study (in September), the highest number of shorebirds was observed at GSE, followed by XHZ and HK, with $68.57,16.65$, and $14.78 \%$ of the total count, respectively. More birds were counted at GSE and XHZ than at HK before 10 October 2011, after which the opposite distribution pattern was observed (Figure 2).

3.2. Spatial and Temporal Distribution of Benthic Macroinvertebrates. The most abundant prey in the wetland during both the peak and postpeak shorebird migration was Chironomidae (Table 1).

There were large spatial (horizontal and vertical) and temporal variations in the distributions of benthic macroinvertebrates. Spatially, the Kruskal-Wallis test showed that the density of benthic macroinvertebrates varied significantly between the three sampling sites $(p<0.001)$, with HK
TABLE 1: Mean \pm SD benthic macroinvertebrate densities from the counts at Wuliangsuhai Lake during the autumn migration in 2011 $(n=33)$.

\begin{tabular}{lccc}
\hline Time period & Chironomidae & Lymnaeidae & Others \\
\hline Peak migration & $5,168 \pm 13,392$ & $205 \pm 490$ & $90 \pm 182$ \\
Postpeak migration & $1,303 \pm 1,842$ & $0 \pm 0$ & $0 \pm 0$ \\
\hline
\end{tabular}

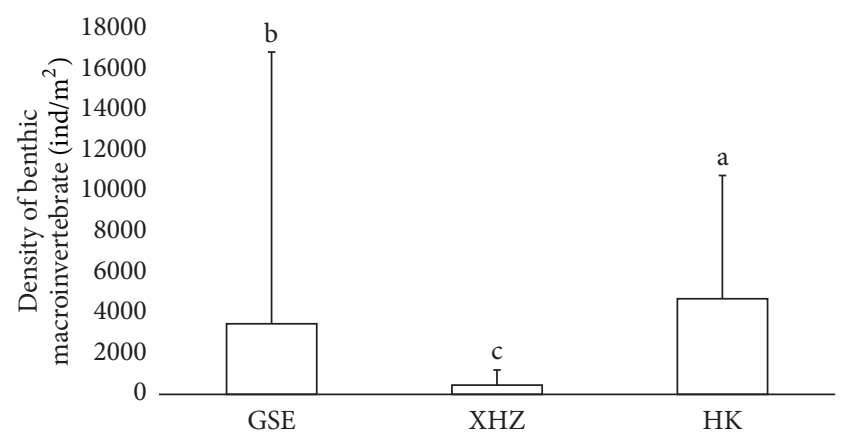

FIGURE 3: Density of benthic macroinvertebrate (mean $\pm \mathrm{SD}$ ) at the three sampling sites of Gesuer (GSE), Xiaohaizi (XHZ), and Hekou (HK) ( $n=30,12$, and 24 for GSE, XHZ, and HK, respectively).

having the highest density and XHZ the lowest (Figure 3). The Mann-Whitney $U$ test showed a significant vertical difference, with a significantly higher density of benthic macroinvertebrates in the top layer of sediment than in the bottom layer $(p<0.001)$ (Figure 4). Temporally, the average density of benthic macroinvertebrates in midSeptember 2011 (5460 indiv. $/ \mathrm{m}^{2}$ ) was substantially higher than in mid-October 2011 (1000 indiv. $\left./ \mathrm{m}^{2}\right)(p=0.005)$. Although Lymnaeidae were largely found in coarse sediments (sand), Chironomidae were mainly found in fine sediments (mud). Sandy-mud could still support a certain amount of Chironomidae (Figure 5).

3.3. Response of Shorebirds to the Distribution of Benthic Macroinvertebrates. Permutation linear regression analyses showed that among the three groups of benthic macroinvertebrates, only Chironomidae showed a positive correlation with shorebird abundance $(p=0.049)$. The model selection procedure using the Akaike information criterion indicated that Lymnaeidae were needed in the regression, although the permutation test suggested that its effect was nonsignificant $(p=0.074)$. The densities of Chironomidae and Lymnaeidae together explained $53.63 \%$ of the variation in the abundance of shorebirds at Wuliangsuhai Lake during the autumn migration $\left(r^{2}=0.536, p=0.046\right)$.

\subsection{Environmental Factors Influencing the Abundance and Distribution of Benthic Macroinvertebrates}

3.4.1. Water Quality. A wide range of environmental gradients was evident across the three sampling sites, most noticeably salinity $(p=0.022$, Table 2$)$, ranging from brackish to supersaline $(5,887-42,600 \mathrm{mg} / \mathrm{L})$. A range of 
TABLE 2: Mean \pm SD values of the principal water quality characteristics across the three sampling sites within the lake: Gesuer (GSE), Hekou $(\mathrm{HK})$, and Xiaohaizi $(\mathrm{XHZ})(n=11)$.

\begin{tabular}{|c|c|c|c|c|c|c|c|}
\hline Sampling site & $\begin{array}{c}\text { Water } \\
\text { temperature } \\
\left({ }^{\circ} \mathrm{C}\right)\end{array}$ & $\mathrm{pH}$ & $\begin{array}{c}\text { Dissolved } \\
\text { oxygen (\%) }\end{array}$ & $\begin{array}{l}\text { Chlorophyll a } \\
(\mathrm{mg} / \mathrm{L})\end{array}$ & Salinity (mg/L) & $\begin{array}{c}\text { Total } \\
\text { nitrogen } \\
(\mathrm{mg} / \mathrm{L})\end{array}$ & $\begin{array}{c}\text { Total } \\
\text { phosphorus } \\
(\mathrm{mg} / \mathrm{L})\end{array}$ \\
\hline GSE & $19.32 \pm 0.96$ & $8.87 \pm 0.10$ & $96.92 \pm 15.34$ & $12.41 \pm 2.30$ & $29,660 \pm 13,076$ & $4.36 \pm 0.59$ & $0.282 \pm 0.032$ \\
\hline HK & $15.98 \pm 1.15$ & $9.34 \pm 0.54$ & $76.8 \pm 15.0$ & $4.04 \pm 1.04$ & $5,887 \pm 537$ & $1.47 \pm 0.09$ & $0.070 \pm 0.011$ \\
\hline XHZ & $19.15 \pm 0.75$ & $9.04 \pm 0.02$ & $83.3 \pm 16.7$ & $7.80 \pm 3.02$ & $42,600 \pm 2,500$ & $12.4 \pm 1.0$ & $0.356 \pm 0.000$ \\
\hline
\end{tabular}

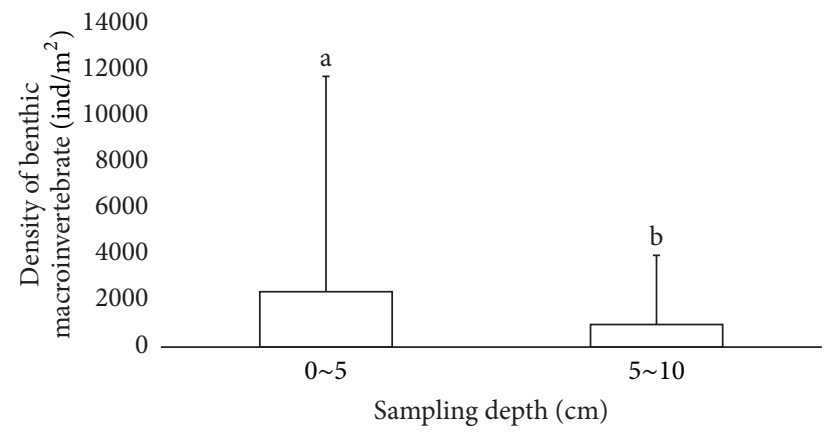

FIgURE 4: Density of benthic macroinvertebrates (mean \pm SD) at sediment depths of $0-5$ and $5-10 \mathrm{~cm}(n=66)$.

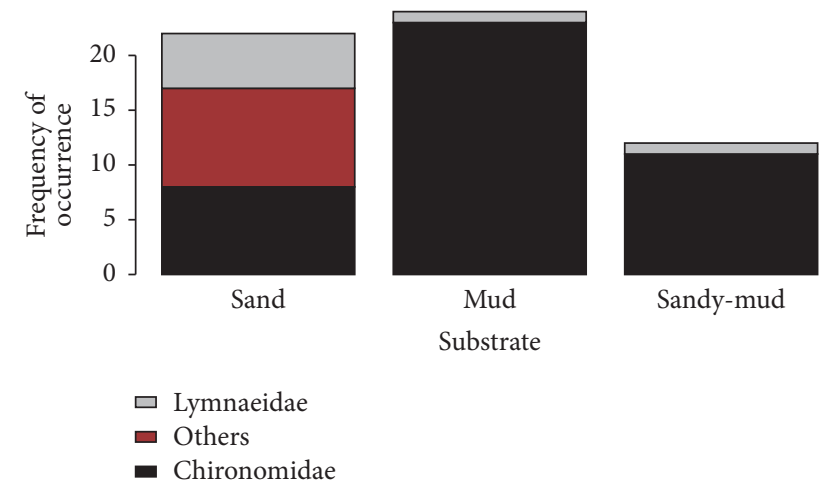

FIGURE 5: Frequency of occurrence of benthic macroinvertebrates in different substrate types during benthic coring within each sample plots $(n=66)$.

concentrations of Chl a $(p=0.024)$, TN $(p=0.014)$, and TP $(p=0.013)$ was also evident, with the concentrations at GSE (12.41, 4.36, and $0.282 \mathrm{mg} / \mathrm{L}$ for $\mathrm{Chl}$ a, TN, and TP, respectively) and XHZ (7.80, 12.4, and $0.356 \mathrm{mg} / \mathrm{L}$ for Chl a, TN, and TP, respectively) significantly higher than those at $\mathrm{HK}(4.04,1.47$, and $0.070 \mathrm{mg} / \mathrm{L}$ for $\mathrm{Chl} \mathrm{a}$, TN, and TP, respectively). The water temperature at GSE and XHZ was $3.00^{\circ} \mathrm{C}$ higher than at $\mathrm{HK}(p=0.030)$. The range of dissolved oxygen concentrations was not significantly different among three sampling sites $(76.8-96.92 \%, p=0.377)$, nor was the $\mathrm{pH}(8.87-9.34, p=0.187)$ (Table 2).

3.4.2. Substrate Quality. The concentrations of N, P, and $\mathrm{OM}$ in the sediment varied significantly among the three sampling sites $(p=0.042, p<0.001$, and $p<0.001$, respectively), with the concentration of $\mathrm{N}$ and $\mathrm{OM}$ highest at $\mathrm{HK}$ and the concentration of $\mathrm{P}$ highest at GSE. The concentrations of all the heavy metals $(p<0.001)$, except $\mathrm{Hg}(p=0.051)$, were significantly different among the three sampling sites, with the concentrations at XHZ and GSE higher than those at HK. The concentrations of $\mathrm{Li}$ in the upper layer of the sediments were significantly higher than in the bottom layer $(p=0.010)$, whereas the concentrations of $\mathrm{Co}$ and $\mathrm{Ni}$ were higher in the deeper sediments $(p=0.036)$ (Table 3$)$.

\subsubsection{Effects of Environmental Variables on Benthic Macroin-} vertebrates. Six environmental variables were included in the final CCA (Figure 6). The first two canonical axes collectively explained $87.5 \%$ of the variance in benthic macroinvertebrate distribution (60.2 and 27.3\% for axes 1 and 2, respectively). Water temperature, salinity, TP, and $\mathrm{Cu}$ were significantly positively correlated with axis 2 (Table 4 ) and axis 2 was positively associated with Chironomidae (Figure 6). From Figure 6, it is clear that Chironomidae were mainly found at sampling sites with a higher water temperature and a higher concentration of both water TP and sediment $\mathrm{P}$, but with a lower concentration of $\mathrm{Cu}$ and a lower water $\mathrm{pH}$. By contrast, Lymnaeidae were largely found at sites with a higher water $\mathrm{pH}$, but with a lower water temperature, lower water TP and salinity, and sediment P. Other macroinvertebrate species (e.g., the larvae of Tabanidae and Tubificidae) mainly occurred at sites with higher concentrations of $\mathrm{Cu}$ and higher salinity (Figure 6). The permutation test also indicated that there was a significant relationship between macroinvertebrate density and water/sediment quality $(p=0.013)$.

\section{Discussion}

4.1. Factors Influencing the Abundance and Distribution of Benthic Macroinvertebrates. The abundance of benthic macroinvertebrates was generally lower at sites that had poorer water and sediment quality, with the abundance decreasing from HK (near the outlet with higher water and sediment quality than other sites), to XHZ (near the drainage inlet with the highest concentrations of nutrients and pollutants). A similar tendency has been reported within the wetland, with the density and biomass of macroinvertebrates increasing with increasing distance from the main sources of pollution [33]. Among the recorded benthic macroinvertebrates, Chironomidae and Lymnaeidae had higher abundances at sites close to the outlet of the wetland where the salinity, TN, TP, and heavy metal (in particular $\mathrm{Cu}$ ) concentrations were much lower than at XHZ and GSE. The pattern 
TABLE 3: Mean \pm SD values of the principal substrate quality characteristics across the three sampling sites within the lake (Gesuer (GSE), Hekou (HK), and Xiaohaizi (XHZ)) in sediments from depths of $0-5$ and 5-10 $\mathrm{cm}(n=15,12$, and 6 for GSE, HK, and XHZ, respectively).

\begin{tabular}{lcccccc}
\hline \multirow{2}{*}{ Substrate characteristic } & \multicolumn{2}{c}{ GSE } & \multicolumn{2}{c}{ HK } & \multicolumn{2}{c}{ XHZ } \\
& $0-5 \mathrm{~cm}$ & $5-10 \mathrm{~cm}$ & $0-5 \mathrm{~cm}$ & $5-10 \mathrm{~cm}$ & $0-5 \mathrm{~cm}$ & $5-10 \mathrm{~cm}$ \\
\hline Organic matter $(\%)$ & $1.33 \pm 0.62$ & $1.17 \pm 0.43$ & $3.22 \pm 1.36$ & $1.97 \pm 0.85$ & $2.30 \pm 1.03$ & $1.59 \pm 0.54$ \\
$\mathrm{~N}(\mathrm{mg} / \mathrm{kg})$ & $1362 \pm 703$ & $717 \pm 202$ & $1508 \pm 637$ & $1403 \pm 863$ & $1134 \pm 370$ & $1001 \pm 242$ \\
$\mathrm{P}(\mathrm{mg} / \mathrm{kg})$ & $916.2 \pm 69.6$ & $972.30 \pm 83.84$ & $835.85 \pm 59.16$ & $818.98 \pm 54.06$ & $804.53 \pm 29.72$ & $866.23 \pm 54.65$ \\
$\mathrm{As}(\mathrm{mg} / \mathrm{kg})$ & $21.14 \pm 5.81$ & $25.98 \pm 7.56$ & $9.20 \pm 1.99$ & $12.30 \pm 3.60$ & $29.68 \pm 4.26$ & $35.30 \pm 5.98$ \\
$\mathrm{Co}(\mathrm{mg} / \mathrm{kg})$ & $10.67 \pm 2.30$ & $12.20 \pm 2.44$ & $8.92 \pm 1.39$ & $9.46 \pm 1.13$ & $11.49 \pm 0.52$ & $12.81 \pm 0.59$ \\
$\mathrm{Cu}(\mathrm{mg} / \mathrm{kg})$ & $26.63 \pm 6.19$ & $30.93 \pm 10.82$ & $19.69 \pm 4.10$ & $21.12 \pm 3.51$ & $33.26 \pm 3.84$ & $37.20 \pm 11.71$ \\
$\mathrm{Li}(\mathrm{mg} / \mathrm{kg})$ & $40.60 \pm 5.47$ & $44.46 \pm 6.72$ & $37.08 \pm 8.14$ & $37.44 \pm 6.51$ & $49.78 \pm 2.20$ & $51.97 \pm 3.27$ \\
$\mathrm{Ni}(\mathrm{mg} / \mathrm{kg})$ & $30.28 \pm 6.72$ & $34.61 \pm 7.59$ & $26.74 \pm 4.64$ & $27.94 \pm 4.29$ & $31.25 \pm 1.48$ & $34.63 \pm 2.89$ \\
$\mathrm{Hg}(\mathrm{mg} / \mathrm{kg})$ & $0.01 \pm 0.00$ & $0.02 \pm 0.00$ & $0.01 \pm 0.01$ & $0.01 \pm 0.00$ & $0.01 \pm 0.00$ & $0.01 \pm 0.00$ \\
\hline
\end{tabular}

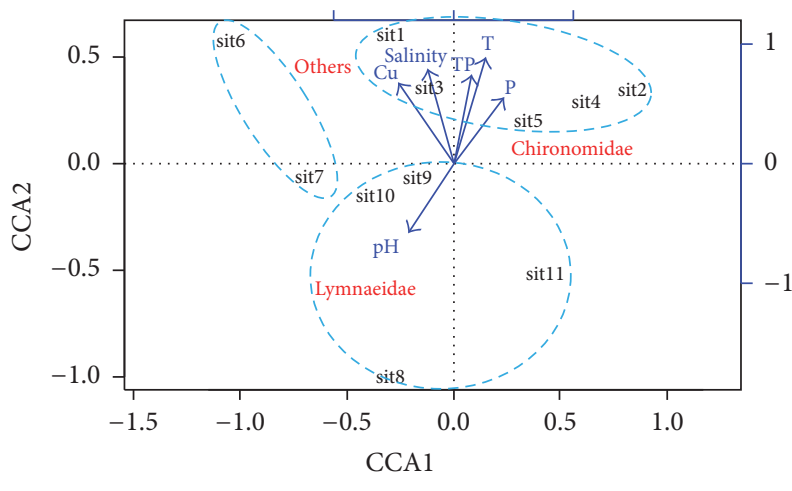

Figure 6: Plot of first two axes of canonical correspondence analysis (CCA) ordination based on the log-transformed benthic macroinvertebrate density data and environmental variables (arrows) at different sites.

TABLE 4: Correlation coefficients of environmental variables with the first two axes of canonical correspondence analysis.

\begin{tabular}{lcc}
\hline Environmental variable & \multicolumn{2}{c}{ Axis } \\
& 1 & 2 \\
\hline pH & -0.58418 & -0.81162 \\
Water temperature & 0.31746 & $0.94827^{* *}$ \\
Salinity & -0.29459 & $0.95562^{*}$ \\
Total phosphorus & 0.20732 & $0.97827^{*}$ \\
$\mathrm{P}$ & 0.63746 & 0.77048 \\
$\mathrm{Cu}$ & -0.60334 & $0.79748^{*}$ \\
\hline
\end{tabular}

Significance at ${ }^{*} p<0.05$ and ${ }^{* *} p<0.01$.

was particularly clear for Lymnaeidae, which was absent from the majority of sampling plots at XHZ. This indicates that Lymnaeidae have a relatively higher requirement for water and substrate quality than Chironomidae and that high levels of salinity and TP or heavy metals could restrict the survival of Lymnaeidae [34]. Some species of Chironomidae larvae can tolerate very high levels of pollution $[35,36]$ and they often become the dominant group of benthic invertebrates in polluted water bodies such as Wuliangsuhai Lake.
Benthic invertebrates are strongly affected by environmental stress, such as inorganic contaminants [37] - for example, the accumulation of heavy metals in sediments could lead to the death of benthic invertebrates [38]. Several effects of metal contamination on benthic communities have been documented, including decreased density [39, 40], a reduction in the number of sensitive taxa [41], and changes in the distribution patterns of species [42]. Our study suggested that water temperature, salinity, TP, and $\mathrm{Cu}$ concentrations in sediments were the most important variables in determining the density and distribution of benthic macroinvertebrate. Other variables, such as water $\mathrm{pH}$ and the $\mathrm{P}$ concentration in the sediment, might be less important for benthic macroinvertebrate at Wuliangsuhai Lake. $\mathrm{pH}$ does not play an important part in determining the distribution of Lymnaeidae in natural water bodies [34]. Although the CCA indicated that the sediment $\mathrm{P}$ concentration did not have a positive relationship with the density of benthic macroinvertebrates, this result should be interpreted with caution. Because the sediment $\mathrm{P}$ and water TP were highly positively correlated, which is consistent with the study of Sun et al. [43], the negative relationship between the water column TP and the abundance of benthic macroinvertebrates might imply a negative relationship between the sediment $\mathrm{P}$ and the abundance of benthic macroinvertebrates. Previous studies have shown that the amount of sediment $\mathrm{P}$ at Wuliangsuhai Lake may be a threat to the benthic communities and may have exacerbated the eutrophic level of the water body [44].

The concentration of $\mathrm{Cu}$ had a more significant effect on the benthic macroinvertebrates than other heavy metals. In a study of benthic fauna and pollutant levels in Norwegian fjords, Brage [45] also found that $\mathrm{Cu}$ had the highest deleterious effect. The high $\mathrm{Cu}$ level in the top $5 \mathrm{~cm}$ of sediments sampled from GSE and XHZ was evidence of slight to moderate heavy metal pollution [46]. The substrate type also played an important part in determining the species, abundance, and distribution of benthic invertebrates [47]. Chironomidae larvae preferred muddy substrates, whereas Lymnaeidae preferred sandy substrates at Wuliangsuhai Lake.

The loading of nutrients (especially TP) and heavy metals (in particular $\mathrm{Cu}$ ) into the aquatic environment has increased with the intensity of human activities. The input of nutrients 
into Wuliangsuhai Lake is mainly from irrigation drainage water [20] and the source of heavy metals is mainly from industrial wastewater and domestic sewage around the wetland [48]. As a result, the diversity and distribution of benthic macroinvertebrates may have changed. Some species may even disappear locally when pollution exceeds their tolerance level. For example, Lymnaeidae were absent from most sampling plots at XHZ. As demonstrated in this and many previous studies [49-51], shorebirds positively follow the distribution pattern of benthic macroinvertebrates and therefore changes in the benthic macroinvertebrate communities might eventually lead to the functional loss of Wuliangsuhai Lake as a stopover site for migratory shorebirds. Reducing the nutrient loadings and controlling water pollution are crucial for waterbird conservation at Wuliangsuhai Lake.

4.2. Distribution of Shorebirds and Relationship with Benthic Macroinvertebrates. Our results showed that the distribution of shorebirds at Wuliangsuhai Lake was not random, with the greatest abundance of shorebirds at GSE, the main foraging habitat during peak migration. However, in mid-October 2011, after the peak season when most shorebirds had left, $\mathrm{HK}$ provided the main foraging habitat for late migrants [12] (Figure 2). These two main foraging areas also had the highest abundance of benthic macroinvertebrates (Figure 3). Numerous studies have shown positive relationships between shorebirds and prey abundance or biomass, but the strength of the relationship varies among studies $[52,53]$. Our study confirmed the numerical relationship between shorebirds and benthic macroinvertebrates within Wuliangsuhai Lake, even though the relationship was not very strong (the $r^{2}$ value of the multiple linear regression was moderate $53.63 \%$ ), which may be due to the relatively small sample size (only during autumn migration). Prey density alone is unlikely to account for all the variation in bird density [54] - for example, GSE had the highest average shorebird density, but not the highest average prey density. Other variables, such as vegetation cover [55] and prey availability, which are associated with water depth [56], should be incorporated into future studies. Determination of the dynamic interaction between shorebirds and the density of benthic macroinvertebrates (e.g., sites with more abundant macroinvertebrates would attract more shorebirds, which, in turn, could suppress the abundance of macroinvertebrates) would give a better insight into the ecological communities and help in the conservation of the wetland ecosystem.

Many shorebird species are long-distance migrants and require high-quality stopover sites to rest and refuel for their next journey. One of the most important factors is the availability of food at the stopover sites [57]. It is also known that the interactions among shorebirds, their prey, and the environment are important $[6,58-61]$ and provide basic information for the management of shorebird habitats. The populations of long-distance migratory shorebirds around the world are decreasing [62] and some of the steepest and most widespread declines have been observed in the East Asian-Australasian Flyway [63]. Most of the earlier studies have focused only on shorebirds and their habitats in the coastal zones of the flyway $[5,64,65]$ and there is little information available on inland wetlands. Our study focused on the numerical relationship between shorebirds and benthic macroinvertebrates in a temperate arid wetland and provides important data for future studies.

\section{Conclusions}

The abundance of both shorebirds and benthic macroinvertebrates at Wuliangsuhai Lake varied significantly in space and time. Environmental factors, including the water and substrate quality, had strong impacts on the abundance and distribution of benthic macroinvertebrates. The shorebirds positively followed the distribution patterns of the benthic macroinvertebrates. Thus, the numerical relationship between shorebirds and benthic macroinvertebrates within Wuliangsuhai Lake was confirmed. Our findings suggest that reducing the nutrient and heavy metal loadings is crucial in maintaining the ecological function of Wuliangsuhai Lake as a foraging and stopover habitat for migratory shorebirds.

\section{Competing Interests}

The authors declare that there is no conflict of interests regarding the publication of this paper.

\section{Acknowledgments}

During this study, the first author was supported by the Special Foundation for Basic Scientific and Technological Research Program (2013FY111800). The authors gratefully acknowledge the help provided by the Administration of Wuliangushai Nature Reserve to access the study site and provide facilities for the surveys. Their thanks are especially given to Mr. YingshouXu, Dr. YifeiJia, and Yunzhu Liu for assistance during the fieldwork and to Meng Yang and Nana Li for laboratory assistance.

\section{References}

[1] P. Evans and P. Dugan, Coastal Birds: Numbers in Relation to Food Resources, Cambridge University Press, Cambridge, UK, 1983.

[2] K. Grond, Y. Ntiamoa-Baidu, T. Piersma, and J. Reneerkens, "Prey type and foraging ecology of Sanderlings Calidris alba in different climate zones: are tropical areas more favourable than temperate sites?” PeerJ, vol. 3, no. 8, Article ID el125, 2015.

[3] P. R. Evans, "Energy balance and optimal foraging strategies in shorebirds: some implications for their distributions and movements in the non-breeding season," Ardea, vol. 64, pp. 117139, 1976.

[4] T. Piersma, "Energetic bottlenecks and other design constraints in avian annual cycles," Integrative and Comparative Biology, vol. 42, no. 1, pp. 51-67, 2002.

[5] H.-Y. Yang, B. Chen, Z.-J. Ma et al., "Economic design in a longdistance migrating molluscivore: how fast-fuelling red knots in Bohai Bay, China, get away with small gizzards," Journal of Experimental Biology, vol. 216, no. 19, pp. 3627-3636, 2013. 
[6] M. A. Colwell and S. L. Landrum, "Nonrandom shorebird distribution and fine-scale variation in prey abundance," The Condor, vol. 95, no. 1, pp. 94-103, 1993.

[7] C. Holling, "A model of the functional response of predator to prey density involving the hunger effect," The Canadian Entomologist, vol. 91, pp. 385-398, 1959.

[8] J. A. Alves, T. G. Gunnarsson, D. B. Hayhow et al., "Costs, benefits, and fitness consequences of different migratory strategies," Ecology, vol. 94, no. 1, pp. 11-17, 2013.

[9] I. Newton, The Migration Ecology of Birds, Academic Press, 2010.

[10] J. A. Alves, W. J. Sutherland, and J. A. Gill, "Will improving wastewater treatment impact shorebirds? Effects of sewage discharges on estuarine invertebrates and birds," Animal Conservation, vol. 15, no. 1, pp. 44-52, 2012.

[11] H. Rousi, H. Peltonen, J. Mattila, S. Bäck, and E. Bonsdorff, "Impacts of physical environmental characteristics on the distribution of benthic fauna in the northern Baltic sea," Boreal Environment Research, Supplement B, vol. 16, p. 521, 2011.

[12] Z. Yamian, J. Yifei, J. Shengwu et al., "Wuliangsuhai wetlands: a critical habitat for migratory water birds," Journal of Resources and Ecology, vol. 3, no. 4, pp. 316-323, 2012.

[13] W. P. Li, C. Y. Li, X. H. Shi, and B. Cui, "Analysis of distribution features of nitrogen and phosphorus nutritous elements and their geochemical environment for Wulangsu Lake, Inner Mongolia," Resources Survey \& Environment, vol. 29, no. 2, pp. 131-138, 2008.

[14] Q. Luo and C. Y. Li, "Seasonal variation and distribution of chlorophyll-a in WuliangsuHai Lake," Water Saving Irrigation, no. 2, pp. 36-39, 2011.

[15] Y. Cao, S. Shang, J. Yang, L. Wu, H. Liu, and K. Luan, "Research on Spatial and Temporal Dynamic Evolution of Wuliangsuhai Lake Wetland," Progress in Geography, vol. 29, no. 3, pp. 307-311, 2010.

[16] Y. Ruihong, L. Tingxi, X. Youpeng, and L. Changyou, "The impacts of human activities on the Wuliangsuhai wetland environment," Journal of Lake Sciences, vol. 19, no. 4, pp. 465472, 2007.

[17] Y. Q. Pan, L. L. Xing, and G. S. Yang, "A preliminary study on Avifauna's evolution in Wuliangsuhai Wetland during the last 10 years," Acta Scientiarum Naturalium Universitatis NeiMongol, vol. 37, pp. 170-174, 2006.

[18] Z. Y. Liu, Research about Estimating the Input to the Lake Wuliangsuhai from Farmland Surface Pollution, Inner Mongolia University, Hohhot, China, 2004.

[19] Y. X. Qiu, The Study on the Issue of Harnessing Wuliangsu Lake by International Co-Operation, Inner Mongolia Universtiy, Hohhot, China, 2007.

[20] Z. Wang, "Water body nitrogen and phosphorus pullution and control measures at Wuliangsuhai Lake," Inner Mongolia Water Resources, no. 2, pp. 8-9, 2013.

[21] B. W. Xiao, W. L. Cheng, R. Yao, H. M. Liu, and Y. H. Liu, "Study on variation trend of nitrogen and phosphorus in Wuliangsuhai lake of Inner Mongolia," Journal of Water Resources \& Water Engineering, vol. 26, pp. 43-46, 2015.

[22] Q. Zeng, Y. Zhang, Y. Jia et al., "Zoning for management in wetland nature reserves: a case study using wuliangsuhai nature reserve, China," SpringerPlus, vol. 1, no. 1, p. 23, 2012.

[23] Y. Q. Pan, L. Li, and H. Y. Zhang, "The study of the ecological service functions assessment of awes habitat in Wuliangsuhai Wetland," Northern Environment, vol. 23, no. 1, pp. 36-38, 2011.
[24] L. L. Xing and G. S. Yang, The Avifauna of Wuliangsuhai in Inner Mongolia, Inner Mongolia Press, 1996.

[25] T. F. Nalepa, D. L. Fanslow, S. A. Pothoven, A. J. Foley III, and G. A. Lang, "Long-term trends in benthic macroinvertebrate populations in Lake Huron over the past four decades," Journal of Great Lakes Research, vol. 33, no. 2, pp. 421-436, 2007.

[26] J. H. Epler, "Identification manual for the larval Chironomidae (Diptera) of North and South Carolina," Febs Letters, vol. 81, no. 2, pp. 427-430, 2001.

[27] R. W. Merritt, K. W. Cummins, and M. B. Berg, An Introduction to the Aquatic Insect of North America, Kendall/Hunt, Dubuque, Iowa, USA, 2008.

[28] Y. Y. Liu, W. Z. Zhang, Y. X. Wang, and S. Y. Wang, China's Economic Animals. Freshwater Mollusks, Science Press, Beijing, China, 1979.

[29] H. Akaike, "A new look at the statistical model identification," IEEE Transactions on Automatic Control, vol. 19, no. 6, pp. 716723, 1974.

[30] R. E. Wheeler, "Permutation tests for linear models in R," 2010.

[31] C. J. F. Ter Braak, "Canonical correspondence analysis: a new eigenvector technique for multivariate direct gradient analysis," Ecology, vol. 67, no. 5, pp. 1167-1179, 1986.

[32] R Develoment Core Team, $R$ : A Language and Environment for Statistical Computing, R Foundation for Statistical Computing, Vienna, Austria, 2014.

[33] Z. H. He, Z. H. Xie, Y. Z. Lei, D. L. Sun, and Z. H. Liu, "A hydrochemical \& hydrobiological survey of the lake Wuliang Su Hai," Journal of Dalian Fisheries University, vol. 1, no. 9, p. 84, 1984.

[34] N. Pullan, F. Climo, and C. Mansfield, "Studies on the distribution and ecology of the family lymnaeidae (Mollusca: Gastropoda) in New Zealand," Journal of the Royal Society of New Zealand, vol. 2, no. 3, pp. 393-405, 1972.

[35] S. K. Mousavi, R. Primicerio, and P.-A. Amundsen, "Diversity and structure of Chironomidae (Diptera) communities along a gradient of heavy metal contamination in a subarctic watercourse," The Science of the Total Environment, vol. 307, no. 1-3, pp. 93-110, 2003.

[36] G. Winberg, Experimental Application of Various Systems of Biological Indication of Water Pollution [in USSR], PB US National Technical Information Service, 1978.

[37] J. S. Richardson and P. M. Kiffney, "Responses of a macroinvertebrate community from a pristine, Southern British Columbia, Canada, stream to metals in experimental mesocosms," Environmental Toxicology and Chemistry, vol. 19, no. 3, pp. 736-743, 2000.

[38] S.-E. Lee, D.-H. Yoo, J. Son, and K. Cho, "Proteomic evaluation of cadmium toxicity on the midge Chironomus riparius Meigen larvae," Proteomics, vol. 6, no. 3, pp. 945-957, 2006.

[39] T. P. Diggins and K. M. Stewart, "Chironomid deformities, benthic community composition, and trace elements in the Buffalo River (New York) area of concern," Journal of the North American Benthological Society, vol. 17, no. 3, pp. 311-323, 1998.

[40] R. W. Winner, M. W. Boesel, and M. P. Farrell, "Insect community structure as an index of heavy metal pollution in lotic ecosystems," Canadian Journal of Fisheries and Aquatic Sciences, vol. 37, no. 4, pp. 647-655, 1980.

[41] T. W. LaPoint, S. M. Melancon, and M. K. Morris, "Relationships among observed metal concentrations, criteria, and benthic community structural responses in 15 streams," Journal of the Water Pollution Control Federation, vol. 56, no. 9, pp. 1030-1038, 1984. 
[42] W. H. Clements, D. S. Cherry, and J. H. Van Hassel, "Assessment of the impact of heavy metals on benthic communities at the Clinch River (Virginia): evaluation of an index of community sensitivity," Canadian Journal of Fisheries and Aquatic Sciences, vol. 49, no. 8, pp. 1686-1694, 1992.

[43] H. M. Sun, J. He, X. D. Gao et al., "Distribution of total phosphorus in sediments of Wuliangsuhai Lake," Acta Sedimentologica Sinica, vol. 24, no. 4, pp. 579-584, 2006.

[44] H. M. Sun, J. He, X. D. Gao, C. W. Lv, Q. Y. Fan, and H. X. Xue, "Distribution of total phosphorus in sediments of Wuliangsuhai Lake," Acta Sedimentologica Sinica, vol. 24, no. 4, pp. 579-584, 2013.

[45] R. Brage, "Effect of sediment copper on benthic fauna," Marine Ecology Progress Series, vol. 25, pp. 83-89, 1985.

[46] EPA (U.S. Environment Protection Agency), "Toxicological benchmarks for screening contaminants of potential concern for effects on sediment-associated biota," Report of the Sediment Criteria Subcommittee, Science Advisory Board ES/ER/TM-95/R4.61, 1997.

[47] D. M. Bezmaternykh and O. N. Zhukova, "Composition, structure, and formation factors of bottom invertebrate communities in lakes of the southern Ob-Irtysh interfluve," Russian Journal of Ecology, vol. 44, no. 2, pp. 170-177, 2013.

[48] S. N. Zhao, C. Y. Li, X. H. Shi, H. M. Zhang, and S. Wang, "Bioavailability and environment pollution evaluation of sediments heavy metals in Wuliangsuhai Lake," Ecology and Environmental Sciences, vol. 22, no. 3, pp. 481-489, 2013.

[49] S. Guareschi, P. Abellán, A. Laini et al., "Cross-taxon congruence in wetlands: assessing the value of waterbirds as surrogates of macroinvertebrate biodiversity in Mediterranean Ramsar sites," Ecological Indicators, vol. 49, pp. 204-215, 2015.

[50] R. J. Safran, C. R. Isola, M. A. Colwell, and O. E. Williams, "Benthic invertebrates at foraging locations of nine waterbird species in managed wetlands of the northern San Joaquin Valley, California," Wetlands, vol. 17, no. 3, pp. 407-415, 1997.

[51] S. Werner, M. Mörtl, H.-G. Bauer, and K.-O. Rothhaupt, "Strong impact of wintering waterbirds on zebra mussel (Dreissena polymorpha) populations at Lake Constance, Germany," Freshwater Biology, vol. 50, no. 8, pp. 1412-1426, 2005.

[52] W. Wolff, "Distribution of non-breeding waders in an estuarine area in relation to the distribution of their food organisms," Ardea, vol. 57, pp. 1-28, 1969.

[53] L. Zwarts, A.-M. Blomert, B. J. Ens, R. Hupkes, and T. M. Van Spanje, "Why do waders reach high feeding densities on the intertidal flats of the Banc d'Arguin, Mauritania?" Ardea, vol. 78, no. 1-2, pp. 39-52, 1990.

[54] G. M. Puttick, Foraging and Activity Patterns in Wintering Shorebirds, 1984.

[55] C. S. Lopes, J. A. Ramos, and V. H. Paiva, "Changes in vegetation cover explain shifts of colony sites by little terns (Sternula albifrons) in Coastal Portugal," Waterbirds, vol. 38, no. 3, pp. 260-268, 2015.

[56] E. Sebastián-González and A. J. Green, "Habitat use by waterbirds in relation to pond size, water depth, and isolation: lessons from a restoration in Southern Spain," Restoration Ecology, vol. 22, no. 3, pp. 311-318, 2014.

[57] T. Piersma, "Using the power of comparison to explain habitat use and migration strategies of shorebirds worldwide," Journal of Ornithology, vol. 148, no. 1, pp. S45-S59, 2007.

[58] J. E. Dugan, D. M. Hubbard, M. D. McCrary, and M. O. Pierson, "The response of macrofauna communities and shorebirds to macrophyte wrack subsidies on exposed sandy beaches of southern California," Estuarine, Coastal and Shelf Science, vol. 58, pp. 25-40, 2003.

[59] S. E. A. L. V. D. Durell, R. A. Stillman, R. W. G. Caldow, S. Mcgrorty, A. D. West, and J. Humphreys, "Modelling the effect of environmental change on shorebirds: a case study on Poole Harbour, UK," Biological Conservation, vol. 131, no. 3, pp. 459473, 2006.

[60] G. L. Hamer, E. J. Heske, J. D. Brawn, and P. W. Brown, "Migrant shorebird predation on benthic invertebrates along the Illinois river, Illinois," Wilson Journal of Ornithology, vol. 118, no. 2, pp. 152-163, 2006.

[61] F. L. Spruzen, A. M. M. Richardson, and E. J. Woehler, "Influence of environmental and prey variables on low tide shorebird habitat use within the Robbins Passage wetlands, Northwest Tasmania," Estuarine, Coastal and Shelf Science, vol. 78, no. 1, pp. 122-134, 2008.

[62] International Wader Study Group, "Are waders world-wide in decline? Reviewing the evidence," Wader Study Group Bulletin, vol. 101-102, pp. 8-12, 2003.

[63] T. Amano, T. Székely, K. Koyama, H. Amano, and W. J. Sutherland, "A framework for monitoring the status of populations: an example from wader populations in the East Asian-Australasian flyway," Biological Conservation, vol. 143, no. 9, pp. 2238-2247, 2010.

[64] M. A. Barter and A. Riegen, "Northward Shorebird Migration Through Yalu Jiang National Nature Reserve," vol. 46, pp. 9-14, 2004.

[65] J. K. Szabo, P. F. Battley, K. L. Buchanan, and D. I. Rogers, "What does the future hold for shorebirds in the East AsianAustralasian Flyway?" Emu Official Organ of the Australasian Ornithologists Union, vol. 116, article 2, 2016. 

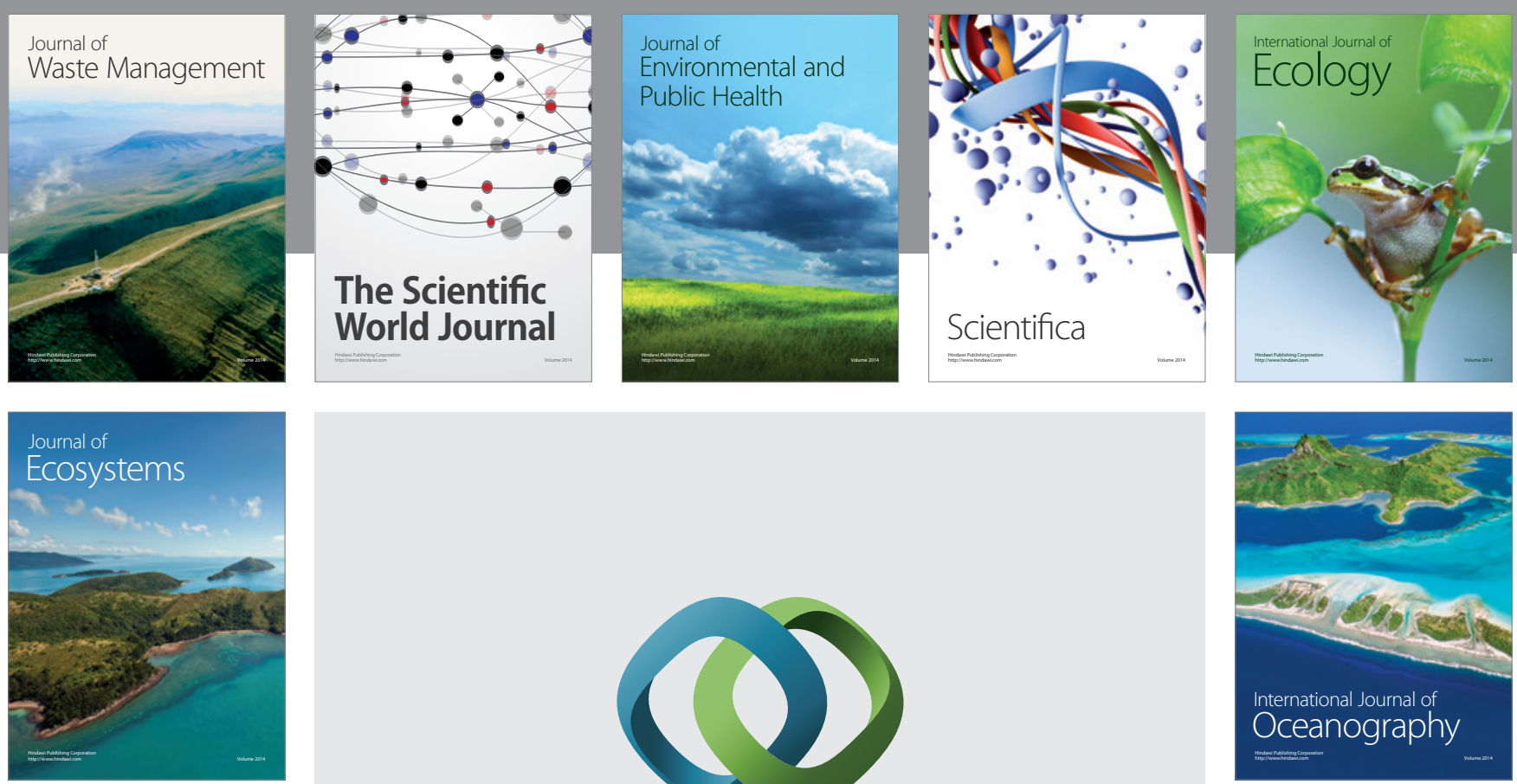

The Scientific World Journal
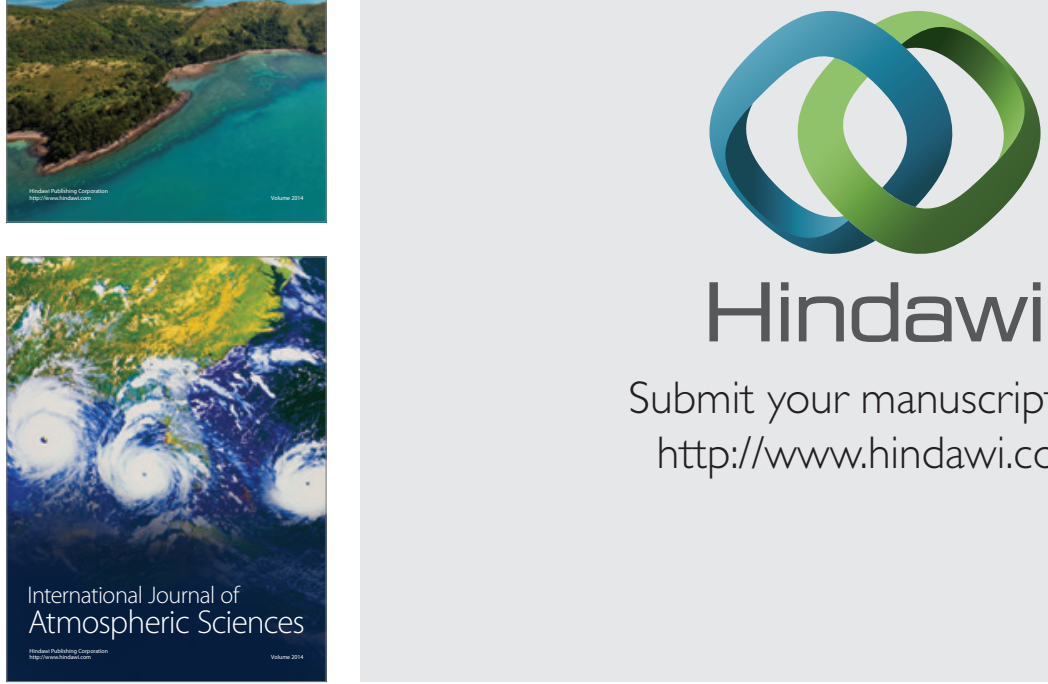

\section{Hindawi}

Submit your manuscripts at

http://www.hindawi.com
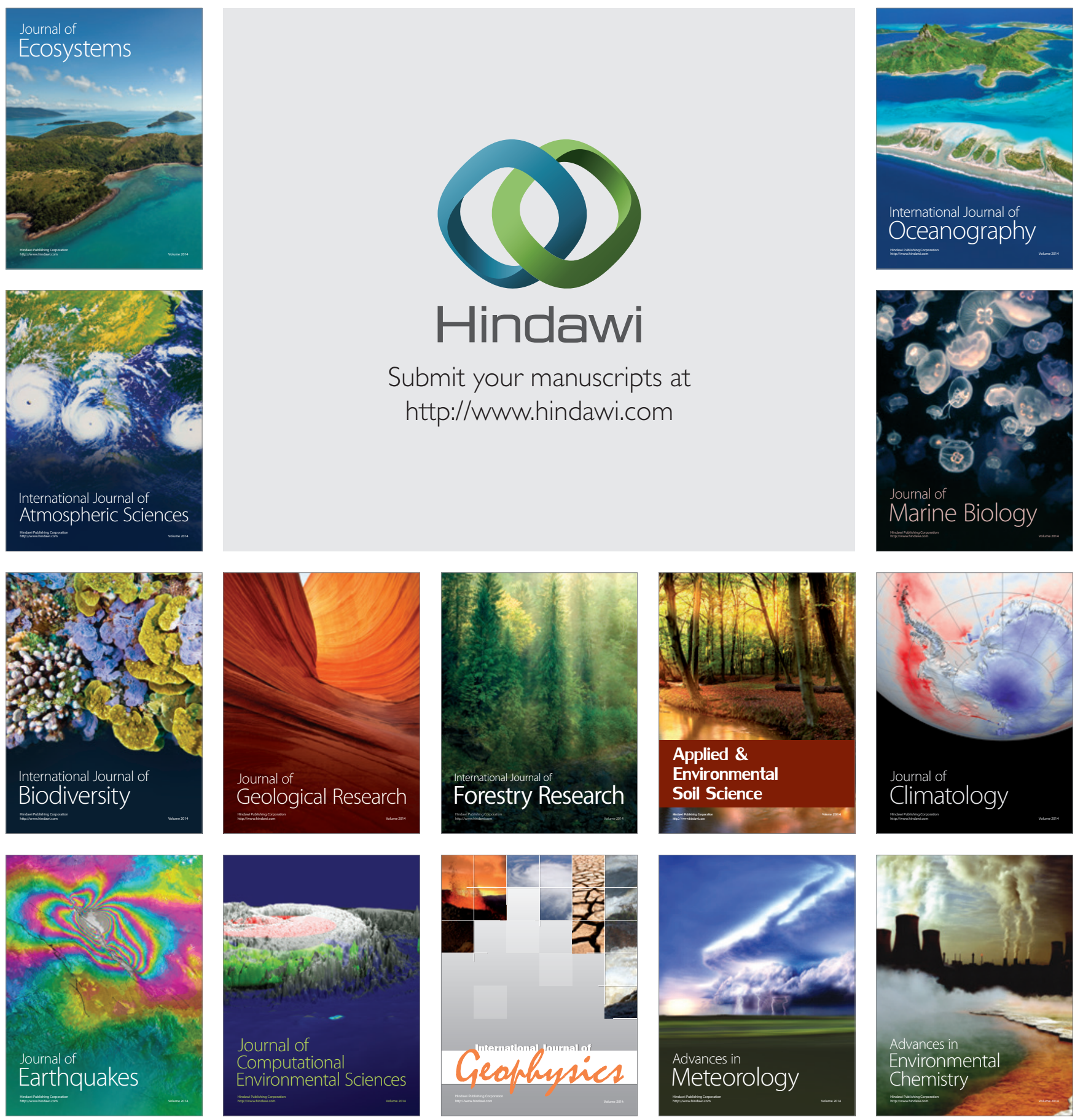